\title{
Shared E-Scooters: A Review of Uses, Health and Environmental Impacts, and Policy Implications of a New Micro-Mobility Service
}

\author{
Alberica Domitilla Bozzi (i) and Anne Aguilera* \\ Laboratoire Ville Mobilité Transport (LVMT), Université Gustave Eiffel and ENPC, 77454 Marne-la-Vallée, France; \\ alberica.domitilla@gmail.com \\ * Correspondence: anne.aguilera@univ-eiffel.fr; Tel.: +33-01-81-66-88-60
}

check for updates

Citation: Bozzi, A.D.; Aguilera, A. Shared E-Scooters: A Review of Uses, Health and Environmental Impacts, and Policy Implications of a New Micro-Mobility Service. Sustainability 2021, 13, 8676. https://doi.org/ $10.3390 /$ su13168676

Academic Editor: Itzhak Benenson

Received: 7 July 2021

Accepted: 30 July 2021

Published: 4 August 2021

Publisher's Note: MDPI stays neutral with regard to jurisdictional claims in published maps and institutional affiliations.

Copyright: (c) 2021 by the authors. Licensee MDPI, Basel, Switzerland. This article is an open access article distributed under the terms and conditions of the Creative Commons Attribution (CC BY) license (https:// creativecommons.org/licenses/by/ $4.0 /)$.

\begin{abstract}
Shared e-scooters refer to a micro-mobility service that enables the short rentals of escooters. The rapid growth of e-scooter sharing has sparked a heated discussion about its role in the urban mobility sector. This article presents a systematic review of the current knowledge on its uses and users, health and environmental impacts, and policy issues. The analysis is based on academic literature, identified with Google Scholar by using keywords and publication years from 2017, and relevant gray literature. Firstly, we highlight that the profiles of e-scooter renters seem to highly match the characteristics of other micro-mobility services users. Secondly, e-scooters are often associated with a high perception of risk from the public and an increasing occurrence of related road accidents. Thirdly, even if promoted as a green mobility option, the true environmental impact of shared e-scooters has only started to be investigated. Early studies point out negative impacts around their production, usage, and maintenance. Fourthly, the integration of shared e-scooters into the existing transport systems requires policy changes, both at the local and national level, including traffic regulations, safety rules, and physical infrastructure. Finally, this paper reveals the ambiguity of the term "e-scooter" and stresses the need for more research, as the future of cities is tied to the development of low-car lifestyles.
\end{abstract}

Keywords: shared e-scooters; micro-mobility services; users and uses; health impacts; environmental impacts; public policy

\section{Introduction}

Standing electric scooters (henceforth e-scooters) are electrically powered vehicles with a handlebar, deck, and wheels. They are light (less than $35 \mathrm{~kg}$ ), travel at a relatively low speed (about $25 \mathrm{~km} / \mathrm{h}$ ), and usually carry only one person (the driver). While e-scooters have been around for years, the possibility of rental is quite recent. Since the launch of the first shared e-scooter schemes in late 2017, e-scooters have become an increasingly popular means of transport for urban residents across the globe [1,2]. In late 2019, shared e-scooter services were available in almost three hundred cities [3].

E-scooters are part of the broad family of the new mobility services supported by information and communication technologies [4]. More precisely, they belong to the micro-mobility modes [5]. According to the International Transport Forum [6], the word "micro" can refer both to the vehicle type (light, with a small footprint) and to the distance travelled (usually short). The term "micro-mobility" encompasses a range of personal, light, low-speed vehicles [7]. Some, such as electric bikes, e-scooters, and hoverboards, are propelled by an electric motor, while others, e.g., conventional bicycles, skates, skateboards, and standing scooters, are solely powered by human energy. Micro-vehicles are often described as new sustainable travel modes with low economic and environmental impacts [8]. Notably, they can contribute to reducing travel time on congested roads, speed up short distance trips, and do not require any driving license. 
Micro-vehicles can be privately owned or shared. Shared micro-mobility services offer people the opportunity to rent a micro-vehicle through a digital platform [8]. These services cover various operational models and transport modes, such as station-based bike sharing and dockless e-scooter sharing, which meet a variety of user needs [9]. E-scooters for hire are the newest shared micro-mobility service. Bird, a company based in Santa Monica, California, launched the first service in the fall of 2017 [10]. Its business and operational model is similar to dockless bike sharing services: the providers distribute their vehicles across the city and provide a smartphone app to rent them. Users download the app on their smartphones and enter a credit card for the payment. The app directs customers to the nearest available e-scooter via GPS, and after scanning a QR code to unlock the vehicle, they can start the ride. After completing the ride, customers end their trip on the app and park their e-scooter (nearly) anywhere in the city.

In early 2018, Bird began to expand, and after a year, it was present in about 100 US cities and 11 others worldwide. Over the course of 2018, existing dockless bike providers such as Lime and Jump switched to e-scooter sharing and new e-scooter-only companies emerged $[11,12]$. Paris was one of the first European cities where shared e-scooters were introduced (in June 2018), and after only a year, the city had thirteen operators and a fleet of over 22,000 vehicles [13]. In late 2018, shared e-scooters landed in several other European cities, such as Vienna [14] and Brussels [15], but also in New Zealand [2], Australia [16], and Singapore [17]. Later in 2019, Lime launched the services in South America [18].

The "New Mobility Atlas" by NUMO [19] provides a global overview of a range of shared micro-mobility services, i.e., dockless e-scooters, bicycles, and moped scooters. It shows that in July 2020, e-scooter services were available in about 390 cities in all regions of the world, except Africa, though nine out of ten cities offering this service were in Europe or North America. Moreover, the Atlas reveals that e-scooters were more widespread than dockless bikes (available in slightly fewer than 300 cities) and moped scooters (found in 84 cities). Interestingly, shared bike services were more widespread than e-scooter services only in Asia. Overall, shared mopeds were the least popular micro-mobility service and were concentrated in Europe anyway.

While it has been claimed that e-scooter ridership has been rising at an unprecedented pace, there are very few actual figures on e-scooter trips. However, since 2018, the National Association of City Transportation Officials (NACTO) has included e-scooter data in its statistics on the growth and use of shared micro-mobility in the US. One year after their introduction, people in the US took more trips using dockless e-scooters than with stationbased bikes [12]. Between 2018 and 2019, e-scooter ridership in the US increased by 120\%, from 38.5 to 88.5 million trips [20]. By comparison, growth in electric bikeshare has been rapid over the last decade with growth rates of approximately $25 \%$, reaching 40 million trips in 2019 [20].

Venture capital has played a major role in the development of shared e-scooter services [21]. Ride-hailing services such as Uber and Lyft have invested large sums on shared micro-mobility companies in order to increase their portfolio of services [12,22]. The Boston Consulting Group found that, between late 2017 and 2018, a dozen e-scooter start-ups attracted more than USD 1.5 billion in funding [23]. In the early stages, these large injections of finance enabled the e-scooter companies to roll out large fleets in a short period of time. According to one report [11], this led to more convenient access for users and ultimately to faster adoption rates.

Currently, usage patterns, user profiles, the social and environmental impacts of micro-mobility services, and the best practices for regulating their use are only partially analyzed $[7,24,25]$. While these issues have now been extensively explored for bicycles and e-bikes [26,27], the role of shared e-scooters in urban mobility practices and policies remains poorly understood, because at present, they represent a relatively new feature of the mobility landscape. However, the sector has developed very quickly, and a growing body of literature is delving into these questions [28]. Existing studies examined e-scooters from a particular angle. For instance, medical reports focused on physical injuries, other articles 
looked at usage patterns and users, safety, regulations, or environmental sustainability. Most recently, Şengül and Mostofi [29] presented an exhaustive review about the field of e-scooters and e-bikes, with a focus on current travel behaviors, energy consumption, urban environment, safety issues, and regulations.

This article presents the current state of knowledge and discusses future research avenues on shared electric scooters (e-scooters) in terms of user and usage characteristics, health impacts, environmental sustainability, and policy issues. In this article, we aimed to provide a broad-yet initial—overview about the impacts and role of shared e-scooter services. The article is organized as follows. Section 2 describes the materials and methods used to select the corpus of documents. Section 3 discusses the profile of the users and the types of uses. Section 4 examines the health impacts. There has been less attention to environmental issues in the literature, so they are only briefly explored in Section 5. More space is given to policy issues in Section 6, reflecting the largest body of materials available on this topic. The key findings are outlined in Section 7, which also proposes several avenues for future research.

\section{Materials and Methods}

Relevant academic articles were identified with the Google Scholar search engine using the following keywords: "e-scooter", "micro-mobility", and "shared". Compared to other academic databases, such as Scopus and Web of Science, Google Scholar includes more resources, but it has also been criticized for including predatory journals in its index. While having to carefully assess the credibility of each source, we decided to use only Google Scholar because it allowed us to include in the corpus the most updated research studies from a broad range of disciplines. The Boolean operators "AND" and "OR" were used to select only papers containing all keywords, including their variations (for instance, "shared" or "sharing"). We customized the search by the date range to include only papers published from 2017, i.e., from the first documented launch of shared e-scooter services anywhere in the world [30] to October 2020. This search resulted in over three hundred records.

As shown in Figure 1, we removed articles that were in languages other than English, not peer-reviewed, and duplicates before screening. After an in-depth review, other articles were removed due to their lack of relevance to our topics of interest: users and usage, health impacts, environmental impacts, and policy issues. Because of the novelty of the subject, we also included gray literature in the search, and backward snowballing was used to select relevant documents [31]. Both authors independently read the documents in detail. After an exchange between them, the final corpus was selected. Moreover, we used the criteria of authenticity, credibility, representativeness, and meaning to limit the risk of bias [32].

In the end, 47 peer-reviewed sources and 23 non-peer-reviewed sources (mainly reports) were selected. A descriptive synthesis was used to compare and analyze the data from these studies. In particular, we performed a structured tabulation to find similarities, differences, and research gaps. Table 1 gives an overview of this corpus, organized by type of source, geographical location of the study area, and topic(s). It shows that, while no geographical restrictions were applied in advance, the selected literature (in English) mainly covers North America and Europe and, less frequently, Oceania and Asia. As briefly mentioned in the previous section, shared e-scooters are currently available mainly in the US and in Europe, which might explain the higher number of publications focusing on these regions. 


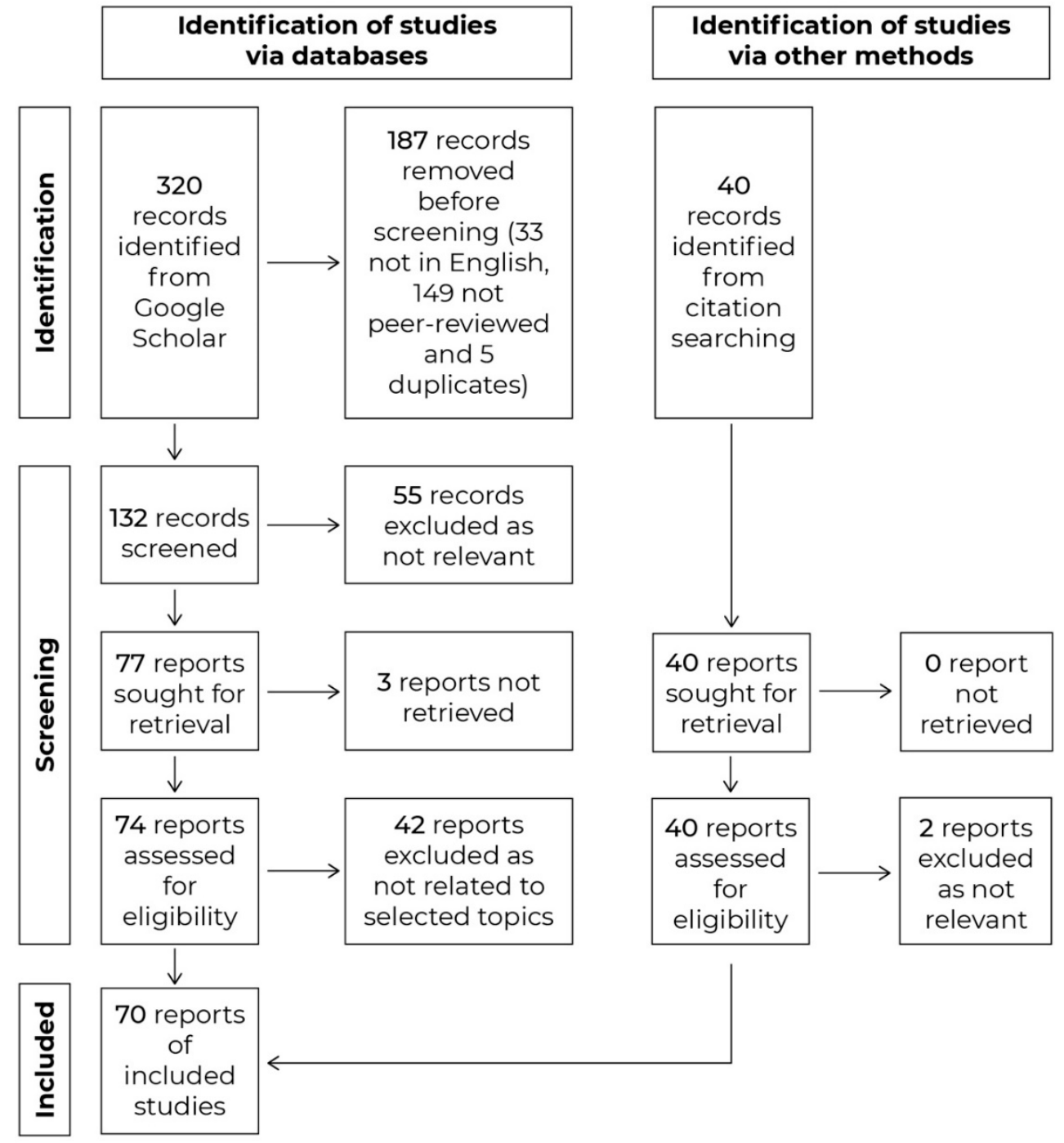

Figure 1. Selection process of the corpus (PRISMA flow diagram).

Table 1. Summary of main sources.

\begin{tabular}{|c|c|c|c|c|c|c|}
\hline Topic & Source Type & North America & Europe & Oceania & Asia & Global \\
\hline \multirow{2}{*}{ Uses and users } & Peer-reviewed & $\begin{array}{l}\text { Bai and Jiao, 2020; } \\
\text { Caspi et al., 2020; } \\
\text { James et al., 2019; } \\
\text { Mathew et al., 2019; } \\
\text { McKenzie, 2019a, } \\
\text { 2020, 2019b; Noland, } \\
\text { 2019; Sanders et al., } \\
\text { 2020; Zou et al., 2020 }\end{array}$ & $\begin{array}{c}\text { Hardt and } \\
\text { Bogenberger, } \\
\text { 2019; Laa and } \\
\text { Leth, 2020; } \\
\text { Ruhrort, 2020 }\end{array}$ & $\begin{array}{l}\text { Curl and Fitt, } \\
\text { 2020; Fitt and } \\
\text { Curl, } 2020\end{array}$ & Zhu et al., 2020 & Davies et al., 2020 \\
\hline & $\begin{array}{c}\text { Not } \\
\text { peer-reviewed }\end{array}$ & $\begin{array}{l}\text { Chang et al., 2019; } \\
\text { Clewlow, 2018; } \\
\text { Espinoza et al., 2019; } \\
\text { Hall, 2017; Lee et al., } \\
\text { 2019; NACTO, 2019, } \\
\text { 2020 }\end{array}$ & $\begin{array}{c}\text { 6t-bureau } \\
\text { de recherche, } \\
\text { 2019; Berge, 2019; } \\
\text { Civity } \\
\text { Management } \\
\text { Consultants, 2019; } \\
\text { Giles, 2020 }\end{array}$ & & & $\begin{array}{l}\text { NUMO, 2020; } \\
\text { Lime, 2018; } \\
\text { Tillemann and } \\
\text { Feasley, } 2018\end{array}$ \\
\hline
\end{tabular}


Table 1. Cont.

\begin{tabular}{|c|c|c|c|c|c|c|}
\hline Topic & Source Type & North America & Europe & Oceania & Asia & Global \\
\hline \multirow[t]{2}{*}{ Health impacts } & Peer-reviewed & $\begin{array}{c}\text { Allem and } \\
\text { Majmundar, 2019; } \\
\text { Alwani et al., 2020; } \\
\text { Badeau et al., 2019; } \\
\text { Bloom et al., 2020; } \\
\text { Glenn et al., 2020; } \\
\text { James et al., 2019; } \\
\text { Kobayashi et al., 2019; } \\
\text { Sikka et al., 2019; } \\
\text { Trivedi et al., 2019 }\end{array}$ & & $\begin{array}{c}\text { Fitt and Curl, } \\
\text { 2020; Haworth } \\
\text { and Schramm, } \\
2019 ; \\
\text { Mayhew et al., } \\
2019 ; \\
\text { Mitchell et al., } \\
2019\end{array}$ & & \multirow[t]{2}{*}{$\begin{array}{c}\text { Neven et al., 2020; } \\
\text { Santacreu et al., } \\
2020\end{array}$} \\
\hline & $\begin{array}{c}\text { Not } \\
\text { peer-reviewed }\end{array}$ & & & & & \\
\hline \multirow[t]{2}{*}{$\begin{array}{l}\text { Environmental } \\
\text { impacts }\end{array}$} & Peer-reviewed & $\begin{array}{l}\text { Hollingsworth et al., } \\
2019\end{array}$ & $\begin{array}{l}\text { de Bortoli and } \\
\text { Christoforou, } \\
\text { 2020; Martínez- } \\
\text { Navarro et al., } \\
\text { 2020; } \\
\text { Moreau et al., } \\
2020\end{array}$ & & & \\
\hline & $\begin{array}{c}\text { Not } \\
\text { peer-reviewed }\end{array}$ & & Berge, 2019 & & & $\begin{array}{c}\text { Rose and } \\
\text { Schellong, } 2020\end{array}$ \\
\hline \multirow[t]{2}{*}{ Policy issues } & Peer-reviewed & $\begin{array}{c}\text { Bartling, 2019; } \\
\text { Brown et al., 2020; } \\
\text { Button et al., 2020; } \\
\text { Hollingsworth et al., } \\
\text { 2019; James et al., } \\
\text { 2019; Janssen et al., } \\
\text { 2020; Noussan et al., } \\
\text { 2020; Riggs and } \\
\text { Kawashima, 2020; } \\
\text { Zou et al., 2020 }\end{array}$ & $\begin{array}{c}\text { de Bortoli and } \\
\text { Christoforou, } \\
\text { 2020; } \\
\text { Florek-Klesk, } \\
\text { 2019; Lipovsky, } \\
2020\end{array}$ & $\begin{array}{l}\text { Haworth and } \\
\text { Schramm, 2019; } \\
\text { Lo et al., } 2020\end{array}$ & Zhu et al., 2020 & $\begin{array}{c}\text { Gössling, 2020; } \\
\text { Li et al., 2020; } \\
\text { Santacreu et al., } \\
\text { 2020; } \\
\text { Shaheen et al., } \\
\text { 2017; } \\
\text { Shaheen et al., } \\
\text { 2020; Shaheen } \\
\text { and Cohen, 2019 } \\
\text { Tice, 2019; Turoń } \\
\text { and Czech, 2020 }\end{array}$ \\
\hline & $\begin{array}{c}\text { Not } \\
\text { peer-reviewed }\end{array}$ & $\begin{array}{l}\text { NACTO, 2020; } \\
\text { Transportation for } \\
\text { America, } 2018\end{array}$ & & & & $\begin{array}{c}\text { Laker, 2019; Reed, } \\
\text { 2019; } \\
\text { Schellong et al., } \\
2019\end{array}$ \\
\hline
\end{tabular}

Finally, it is worth mentioning here that our keyword search revealed a terminological clash. In English, the term "e-scooter" can be used to identify two different vehicles: standing-type e-scooters, which look similar to children's kick scooters but are electric powered, and moped-type e-scooters, which are similar to motorbikes on which the rider sits and were excluded from our analysis. Nonetheless, this terminological ambiguity generated confusion in both academic and non-academic literature. For instance, Degele and colleagues [33] wrote about potential users of shared moped e-scooters in Germany and were cited in a couple of academic papers focused on standing e-scooters $[34,35]$. Similarly, a paper on injuries associated with e-bikes and moped scooters [36] was cited in an article focusing on the impact of standing e-scooters on pedestrian safety [37]. Various attempts have been made to overcome this ambiguity by introducing new classification systems for vehicle types. For instance, a report by the International Transport Forum [6] developed a micro-vehicle taxonomy based on speed and weight.

\section{Usage and Users}

While academic and non-academic studies concur that shared e-scooters are mostly used for very short trips in the afternoon and at weekends, the spatial distribution and purposes of e-scooter trips seem to vary according to the local context. However, analyses of user characteristics are fairly convergent, highlighting the influence of age, gender, and education. They also agree that visitors (i.e., non-residents) represent a significant proportion of users.

\subsection{Usage Patterns}

Based on early data, shared e-scooter trips seem to be mostly short in distance and duration. The US average is about $1.6 \mathrm{~km}$, generally covered in $12 \mathrm{~min}$ [20]. A report on 
European cities calculated the average trip length to be about $1.8 \mathrm{~km}$ [38]. Another report found that half of e-scooter trips in France last less than 15 min [39].

According to the US-based researcher Button and colleagues, shared e-scooter services "often meet a demand that current services do not, or only do so in a second-best way" ([22] p. 3). In fact, the distance travelled by e-scooters is generally perceived as too short for hailing a taxi or taking public transport, and it can also seem too long for walking. Shared e-scooters might, therefore, fill this gap in sustainable transport options for short-distance trips [22,40], which represent an important share of current travel practices by car in North American, British, and German cities [41].

From a temporal perspective, emerging evidence suggests that shared e-scooters are more intensely used in the afternoon rather than the morning [35,42,43]. Moreover, some studies in North America show that average daily usage is higher on weekends and on special days such as public holidays $[35,42,44,45]$. Finally, while the hourly distribution of e-scooter rides shows a long afternoon plateau, the distribution of shared bike usage displays a two-peak pattern, during morning and evening commuting times [45-47].

Spatial patterns of e-scooter trips have been analyzed in more detail in several studies in the US. Mathew et al. [42] studied the origins and destinations of e-scooter trips in Indianapolis. They reported that downtown areas and universities showed heavy e-scooter traffic, and usage peaked in the afternoon. A report in Atlanta [44] analyzed the point of interest (POI) associated with the start and end point of e-scooter trips in order to identify the purposes of travel. The results indicated that e-scooters are primarily used in the afternoon for business and leisure activities. In Austin, a spatio-temporal analysis of e-scooter trips suggested that commuting is not the main trip purpose and that ridership is greater in areas with more students [47]. Finally, Bai and Jiao [40] compared e-scooter use in two major US cities and concluded that, while similarities exist, usage patterns tend to be city-specific.

For the rest of the world, only a few studies are available. A recent study in Singapore [17] found that trips completed by e-scooters have a spatially compact and quantitatively denser distribution compared with shared bikes, and high e-scooter demand correlates with places such as attractions and metro stations. Moreover, while dockless bike sharing is predominantly used for commuting, dock-based e-scooter sharing is mainly used for recreation or tourist activities in the downtown area. Interestingly, the authors noted that the trip purposes for shared bikes and e-scooters are similar in Singapore and Washington D.C., despite the fact that the two cities have inverse operational systems (dockless e-scooters and dock-based bikes in Washington versus dock-based e-scooters and dockless bikes in Singapore).

The evidence regarding trip purposes is mixed, with surveys suggesting that commuting is important, whereas spatio-temporal analyses suggest otherwise. For instance, a survey in France reported that the majority of users hired e-scooters for commuting [39]. Similarly, data from a survey in Vienna suggest that people mainly use e-scooters for work and educational purposes [14]. However, as discussed in the above paragraphs, spatial analyses from different countries indicate that e-scooters are also or even more used more for recreational activities and tourism. The discrepancy between survey results and analyses of trip patterns may be partly explained by considering local specificities, such as land-use patterns [40].

\subsection{User Characteristics}

Since demographic data are not easily shared by service providers, surveys have been conducted to arrive at a better picture of who rides e-scooters. Academic and non-academic sources provide useful and convergent information, such as the age, gender, educational status, and income of e-scooter users. However, some argue that the validity of these surveys might be limited by the method and place of distribution, who responds, and other factors $[14,20]$. 
Overall, the literature reviewed reported that e-scooter users tend to be younger and disproportionally male relative to the general population [2,14,20,39]. For instance, a study in Vienna found that the majority of e-scooter users in Vienna are male, young, and highly educated [14]. Similarly, shared e-scooters in New Zealand seem to appeal more to younger males [48]. Non-academic work in the US [20] and in France [39] showed similar patterns. Moreover, some studies highlighted a positive correlation between e-scooter use and higher levels of education [48,49].

Although these findings show similarities between shared e-scooters and e-bikes, some studies suggest that shared e-scooter services could attract new users to micromobility services. Notably, e-scooters do not require any physical effort to operate, while electric bikes need to be pedaled, which has been proven to be a significant entry barrier for some users [34]. Overall, at least according to one report [11], compared to bike sharing services, e-scooter services might achieve greater gender parity and attract new users among people who are not able (or are reluctant) to make physical effort. Despite these optimistic expectations, initial data on gender distribution of shared e-scooter users show substantial differences according to the local context. For instance, the share of male escooter users is about $56 \%$ in New Zealand [2] and 66\% for French cities [39]. Elsewhere, the gender gap is more pronounced: in Vienna, 75\% of shared e-scooter users are men and only 25\% are women [14]; similarly, in the city of Tricity in northern Poland, about $62 \%$ of e-scooter riders are men and 37\% are women [50].

Interestingly, visitors seem to represent a significant proportion of users. According to a report in France [39], one in four e-scooter users are non-residents. A significant proportion of shared e-scooter use by non-residents has also been reported in other cities such as Washington D.C. [35] and Singapore [17]. This finding is important since local users in general value time-saving factors, while visitors are more attracted by the recreational aspect of e-scooters. In this context, the development of e-scooters is starting to be seen as a way to make some tourist destinations more attractive and to offer a greater diversity of micro-mobility solutions for tourists [51], for instance by replacing certain taxi trips [52].

However, some factors remain unexplored. For instance, there are scarcely any data on ethnicity. In the US, the ethnicity of e-scooter users can vary greatly from city to city [20]. A recent study in Arizona [49] noted that African American and Hispanic respondents were significantly more likely than white respondents to express the intention to try e-scooters, because they were unhappy with existing transport options. According to the authors, these findings underscore the potential role of e-scooters in filling a transport gap and increasing equity in access to transport.

\section{Health Impacts}

Injuries, perceived safety, and physical activity are the three main health issues considered in current academic and non-academic work.

\subsection{Injuries}

A considerable amount of the academic literature on e-scooters looks at physical injuries relating to their use, especially in the US, Australia, and New Zealand. Overall, several articles highlight a sharp increase in the number of injuries from e-scooters since the introduction of shared schemes [53-56]. However, Lipovsky [57] noted that this is not unusual considering that the number of users suddenly surged.

While sparsely examined, the most common cause of injury was a loss of balance or falling $[1,53]$. Injuries to the upper limbs and head were the most common $[16,56]$. Even in countries where the use of helmets is mandatory, e-scooter riders rarely wear protective gear $[16,55,58]$. A recent study in the US examined the official Instagram account of Bird, a leading shared e-scooter company with over 66,000 followers, to determine how much emphasis it placed on safety in its posts [59]. The paper concluded that the lack of protective gear in the company's official postings (both in pictures and comments) had a negative impact among its customers, as it tended to normalize risky behavior. 
From hospitalization records, Trivedi et al. [56] found that $90 \%$ of patients with escooter related injuries sustained them while riding. As evidenced by the profile of e-scooter users discussed in the previous section, patients tend to be young men $[53,56,58,60]$, a demographic group with a statistically proven propensity for risky behavior (e.g., [48]). Besides the riders themselves, other road users are exposed to e-scooter-related injuries. Sikka et al. [37], for example, investigated how e-scooter use affected pedestrian safety. The authors found that certain categories of pedestrians, such as children, seniors, and people with disabilities, might be more vulnerable to this new micro-mobility vehicle. In another study [1], elderly people were found to be disproportionately at risk of tripping over an e-scooter.

Finally, a report by Santacreu et al. [6] looked at data on fatality and injuries related to various vehicles. The authors found that a trip by standing e-scooter or bike in a dense urban area is less likely to result in a traffic fatality than a car or motorcycle trip. Additionally, a trip by shared e-scooter is no more likely to result in a road traffic death than a bicycle trip, although the risk of hospital admission may be higher for e-scooters.

\subsection{Perceived Safety}

Although data suggest that severe injuries and death caused by e-scooters are both similar to those caused by bikes and, anyway, are extremely rare [6], incidences of e-scooter related deaths have been extensively reported in the media. Based on a content analysis of local news items in the US, Europe, and Oceania, Gössling [21] found that safety concerns were dominant in most cities. A similar study in Paris [57] arrived at similar findings: the representation of rental e-scooters in the French mainstream media is generally very negative, most particularly over safety issues. According to the author, newspaper articles tend to give the impression that e-scooters are dangerous - even though data on casualties are deficient-because they report each and every e-scooter fatality.

However, perceptions of e-scooter safety in the population may vary between types of road user. One report [61] found that e-scooter riders generally feel safe in the proximity of e-scooters, while other road users tend to feel unsafe when interacting with e-scooters. Moreover, a study by James et al. [30] suggested that both pedestrians and drivers tend to feel less safe while walking and driving in the vicinity of e-scooters compared with bicycles. Some studies have concluded that the public is not used to this new micro-mobility vehicle and that an adaptation period may be needed before e-scooters are accepted as an ordinary mobility option [61]. Overall, e-scooter safety is likely to improve once users learn to navigate urban traffic [62] and car drivers become accustomed to novel forms of mobility [6]. These findings are important, since both the academic $[63,64]$ and gray literature [39] in different parts of the world identified the feeling of insecurity as a major entry barrier to e-scooter use.

\subsection{Physical Activity}

The fact that e-scooters are an "effort-free" mode of transport is advertised by rental companies as a key advantage. However, it also means that the act of riding e-scooters probably offers few if any fitness benefits [65]. E-scooters could, therefore, have negative consequences for physical activity, especially if they are used instead of walking and cycling. However, this hypothesis is still disputed in academic and non-academic work.

Compared with riding an e-scooter, a person would burn about nine times as much energy walking and about four times as much energy cycling the same distance [66]. Neven and colleagues [67] also expressed concerns that e-scooters might replace more active forms of transport such as walking and cycling. The authors argue that "from the perspective of cardiovascular prevention or the fight against obesity, this is exactly what we do not want" ([67] p. 816). Similarly, one report in Oslo [60] found that e-scooters mainly replaced walking and suggested that their use might have a negative effect on public health (e.g., by enabling sedentary lifestyles). 
On the other hand, some studies have suggested that e-scooters might promote infrastructural changes and, thus, create an environment and culture that facilitate cycling and walking [65]. Moreover, a recent report [39] suggested that users do not necessarily walk less when they start using e-scooters.

Overall, more research is required to find out which modes of transport e-scooters replace and complement, and to illustrate the physical health effects of the adoption of e-scooters.

\section{Environmental Impacts}

The environmental impacts of shared e-scooters have so far received little attention, especially in academic research. However, a growing body of research has revealed that, contrary to initial expectations, shared e-scooters may have negative impacts on the environment $[13,15,68]$. Our corpus encompasses two categories of analysis. The first category compares the environmental impacts of shared e-scooters with other transport modes. The second category assesses which aspects of e-scooters life cycles are the most damaging to the environment and suggests potential areas for improvements.

\subsection{Comparison with Other Transport Modes}

E-scooter rental companies often advertise e-scooters as an eco-friendly mode of transport (e.g., [69]). In particular, as electric-powered vehicles, e-scooters produce no exhaust emissions, unlike internal combustion engine (ICE)-powered modes of transport. However, taking only exhaust emissions into account can be misleading when assessing the overall environmental impacts of various transport modes, and the full life cycle impacts need to be considered. In our corpus, only three academic studies used life cycle assessment (LCA) methods to calculate the environmental performance of shared escooters "from cradle to grave". They evaluated a range of impacts, including acidification, eutrophication, and scarcity of component materials. However, global warming is the type of environmental impact that received the most attention. Calculated as $\mathrm{CO}_{2}$ emitted per passenger per distance travelled, this parameter is particularly useful when comparing the overall carbon footprint of different modes of transport.

US-based researchers at North Carolina State University were among the first to apply LCA to shared e-scooters [68]. They found that using a shared e-scooter produces more greenhouse gas (GHG) emissions per mile than travelling by bus, bicycle, moped, or on foot. In other words, a net reduction in environmental impacts is achieved only when escooters replace car trips. Similar studies in Europe have confirmed that, at present, shared e-scooters have a larger carbon footprint than most alternative transport modes [13,15]. In Paris, shared e-scooters produce much lower GHG emissions than private cars and taxis (respectively, two times and three times less) and slightly less than private mopeds and public buses [13]. However, they emit more than shared bikes, shared moped scooters, trams, fast local trains, and the metro (respectively, two, four, six, and ten times more) [13]. So the impact of e-scooters in the transport system as a whole depends significantly on what kind of trips they replace.

Existing LCA studies—such as the study by Moreau and colleagues [15] in Brusselshave also noted that shared e-scooters have a bigger impact than privately owned ones. According to the authors, there may be two main reasons for this: the lifespan of the private e-scooter is longer, as they are better treated and less exposed to vandalism. In addition, shared e-scooters generate significant additional impacts from rebalancing (collection and distribution of vehicles). The authors also noted that shared e-scooters may trigger more profound societal changes that are not captured in LCA models. In practical terms, early evidence in two European capitals $[13,15]$ suggests that many e-scooter owners bought their micro-vehicle after trying a shared e-scooter and that this phenomenon might ultimately lead to environmental benefits. 


\subsection{Impact Drivers and Possible Improvements}

LCA studies have also looked at the various phases in the life cycle of a shared e-scooter, including materials, manufacturing, transport, rebalancing (collection and distribution), charging, and use. While the impact of the various phases might vary between contexts, research suggests that the environmental impacts are currently dominated by materials, manufacturing processes, and rebalancing.

Materials and manufacturing processes account for half (or more) of the total GHG emissions in Brussels, Raleigh, and Paris $[13,15,68]$. From an environmental perspective, the lithium-ion battery and aluminum frame are the components with the biggest impact [68]. Aluminum in particular has a big impact, because it accounts for almost half of the escooter's weight and is energy intensive to produce [15].

Overall, the impacts of materials and manufacturing phases depend primarily on the lifespan of the vehicle. As e-scooters are relatively polluting to produce, their lifespan needs to be as long as possible in order to be environmentally (and economically) sustainable. According to Moreau and colleagues [15], the design is the main parameter influencing lifespan. The first generation of shared e-scooter models were designed for private use and were, thus, unfit for heavy usage and rough handling [23]. One report [3] found that the first generation of shared e-scooters had a lifespan of only two or three months. The same report suggests that the second generation of shared e-scooter models is far more robust and might last 12 to 24 months. In addition to better vehicle design, regulations could raise the average lifespan of shared e-scooters. For example, cities could enact or enforce anti-vandalism policies to reduce e-scooter misuse or mistreatment [68].

Rebalancing is another key driver of GHG emissions. Under normal conditions of use, e-scooters have to be recharged at least once a day. To accomplish this, e-scooter companies generally pay private contractors to collect vehicles that are out of charge (or in remote locations), recharge them, and distribute them at strategic locations. However, since in most cities these contractors use conventional petrol-based vehicles to transport e-scooters, the impacts from rebalancing can be very high: it accounts for, respectively, $50 \%$ and $40 \%$ of shared e-scooter emissions in Paris and Raleigh [13,68]. In Brussels, rebalancing is the phase with the second biggest impact and is responsible for some $20 \%$ of GHG emissions.

As the lifespan of shared e-scooter continues to increase, the rebalancing phase will probably account for a majority of the impacts in the coming years [15]. Researchers have proposed different ways to optimize this phase. For instance, Hollingsworth and colleagues [68] note that using only fuel-efficient vehicles for collection and limiting it to scooters showing very low battery charge might reduce emissions by over $30 \%$. For their part, Moreau and colleagues [15] propose the development of swappable batteries, which could be transported by e-cargo bicycle, removing the need to collect and redistribute the vehicles themselves. In addition, new charging stations could be installed, equipped with charging devices for e-scooters. Researchers in Spain proposed a photovoltaic recharging dock for shared e-scooters and tested it in the city of Valencia [70]. According to the authors, this system would bring several advantages, such as facilitating the use of e-scooters on longer journeys, using a renewable energy source, and compensating for the loss of battery capacity through ageing.

\section{Policy Issues}

The sudden introduction of e-scooter services brought new and urgent challenges for policymakers at the national and local scale [71]. Most challenges, such as sharing data with policymakers and data use by private companies, are relatively similar across the range of micro-mobility services, especially dockless services [72,73]. However, shared e-scooters also raise specific challenges, for instance, regarding safety. Our corpus provides some insights into current e-scooter policies in different countries, as well as recommendations for policymakers. Four main aspects are considered: legal framework, safety, parking and street design, and data sharing and privacy. 


\subsection{Legal Framework}

When shared e-scooter services were first launched, many countries lacked appropriate policies. To address this, some governments adopted new regulations on the classification of e-scooters and where they may be used. They also specified certain technical requirements relating to the braking system, lights, and maximum speed and to safety issues, such as the obligation to wear a helmet and the minimum age of riders [21]. Turon and Czech [74] provide an overview of the various e-scooter policies applied in Europe and in the United States. In Austria, for instance, e-scooters are treated as bicycles [21], whereas in Germany, they are classified as motor vehicles, but they are not subject to all the rules applicable to a motor vehicle [6]. In the United Kingdom, e-scooters must meet all requirements of a motor vehicle, such as licensing, number plates, and signaling devices [74]. As a result, riding e-scooters on streets and pavements in the UK was prohibited until July 2020, when the first shared e-scooter trials were launched in response to the coronavirus pandemic. If successful, they might lead the government to update the existing laws [75].

At the local level, cities were also largely unprepared for the introduction of e-scooter services and reacted in different ways. As reported by a study of ten cities across the globe [21], they repeatedly had to update regulations several times. After a period of laissez-faire, some cities imposed regulations in reaction to irresponsible riding, vandalism, and other negative aspects of e-scooter use [21,30]. For instance, Paris established permits for e-scooter providers, specified operation zones, and enforced operational standards [57]. Other cities banned e-scooter use temporarily [55]. For instance, the city of San Francisco banned e-scooter services for several months before reintroducing them with several restrictions. Finally, some cities have proactively fostered the launch of these services; for example, Portland, Oregon, has introduced a pilot project to test and manage e-scooter impacts [23].

\subsection{Safety}

Cities need to seek a balance between three key aspects of safety: vehicles, users, and infrastructure [6]. First, it is critical to ensure that these vehicles have the necessary safety and visibility equipment, and that they are regularly inspected. For instance, e-scooters in Germany must be fitted with two independent brakes, a horn, and front and rear lights [76].

Second, several cities have tried to shape user behavior by regulating maximum speeds (around $20-25 \mathrm{~km} / \mathrm{h}$ ), the use of personal protective equipment, and minimum user age. For instance, a recent study in New Zealand found that the introduction of mandatory helmet wearing could increase the perception of safety among non-users and, thus, attract new users [64]. However, as many medical reports have shown, helmet wearing on escooters is fundamental and yet very rare, even in cities where it is compulsory (e.g., [56]). In this case, critics suggest that awareness campaigns might be key (e.g., [6]). Moreover, although the learning curve for these devices is short, it is not non-existent. Training might help inexperienced riders to learn how to drive e-scooters in a less threatening environment and under less time pressure [62].

Third and last, creating a safe micro-mobility network has a positive impact on the safety of all road users, including pedestrians (e.g., [6]). As we discuss in the next paragraph, this would require both investments and spatial redistribution.

\subsection{Parking and Street Design}

One of the biggest challenges facing cities since the introduction of shared micromobility services is where these vehicles should be parked and operated [77]. Because e-scooter services are mostly dockless, they can be picked up and dropped off almost anywhere. A common complaint about shared e-scooters is that they are parked improperly, blocking pedestrian rights of way and creating safety hazards [30]. Many cities have created general regulations (e.g., on parking in delivery zones, not blocking ramps) or specific ones (e.g., park only in designated areas) for where riders are allowed to park e-scooters. Moreover, in some cities, providers are required to inform users about local rules and users 
have to take a photograph of the parked vehicle before completing the trip. An initial study on e-scooter parking practices in four US cities notably found that motor vehicles impede access far more $(24.7 \%)$ than bikes $(0.3 \%)$ and e-scooters $(1.7 \%)$ and suggested that policy makers might adopt a more comprehensive approach to parking reform for all modes on city streets [77].

According to Transportation for America [78], cities should set clear guidelines on where these vehicles can be used and provide the funding or infrastructure necessary to improve safety. However, confusion remains about the best environments for their use [62]. In Germany, Austria, and France, for instance, e-scooters are supposed to travel in bicycle lanes or, if not available, on roads [76]. In New Zealand, by contrast, e-scooters can be used on pavements but not in designated on-road cycle lanes [2]. Despite these discrepancies, several academic papers $[1,53,62]$ have suggested that in order to protect pedestrians, e-scooters should operate not on pavements but in bicycle lanes.

Space allocation for new micro-mobility services is increasingly discussed in the academic literature. Notably, Gössling [21] analyzed news items on e-scooters in ten major cities and found that conflicts over space were the most salient issue after safety. In order to minimize the spatial conflicts created by e-scooters, he suggested a set of regulations, such as use restricted to bicycle infrastructures alone and parking only in designated areas. However, in order to support the modal shift to micro-mobility, Gössling [21] recommends that cities should take certain measures, such as dedicating entire road systems to micromobility and lowering car speed limits. Building on this, Laa and Leth [14] propose that more space in Vienna should be allocated to cycling infrastructure and traffic-calmed zones to promote micro-mobility.

\subsection{Data Sharing and Privacy}

Shared micro-mobility companies collect a huge amount of data that can inform transport policies in several ways. For instance, data on trip destinations could help to identify demand for parking, and trip route data could support the planning and maintenance of cycling networks [6]. Therefore, cities would benefit from access to these data to better inform their decision-making processes. However, shared mobility providers are often not legally bound to provide local authorities with data and, as illustrated in the case of Berlin [79], might be reluctant to share data without specific benefits in return. While there are still few national regulations, cities are starting to require micro-mobility companies to share their data [80].

The data issues associated with e-scooters are no different from other micro-mobility services. Overall, access to e-scooter data is important for assessing their impacts on mobility [81], for integrating this new micro-mobility service with existing mobility options [82], and for integrating them into mobility-as-a-service (MaaS) solutions aimed at reducing private car use. In a recent study on e-scooter policies in ten US cities, Janssen and colleagues [83] found that all the cities analyzed had introduced data sharing requirements. Data are often shared through an application programming interface (API) and include real-time information on vehicle fleets, monthly reports on maintenance, operations, and incidents, and anonymized demographic data on users. Although less discussed, data collection from companies raises user privacy concerns [6,78]: policymakers need to ensure that e-scooter companies cannot share sensitive information about the trips made by users [84].

\section{Key Findings and Avenues for Future Research}

\subsection{Key Findings}

Research on micro-mobility services is developing rapidly, and a number of studies focused on shared e-scooter services has been published in recent years. Drawing on a keyword-based search of academic publications and gray literature (mainly reports), this paper provides a first overview of four key topics around e-scooter services: users and usage, health impacts, environmental impacts, and policy issues. 
The findings show that shared e-scooter services, similar to other micro-mobility services, are used predominantly by young men, especially in North American and European cities (but also on the other continents, with the exception of Africa), for both commuting and recreational purposes. In particular, they seem to serve the needs of the tourists in many cities. Moreover, similar to other micro-mobility services, shared e-scooters meet the public need for efficient and flexible ways to quickly cover short distances from origin to destination or to/from public transport hubs. For this reason, they might contribute to multimodal and car-free behaviors [85].

However, e-scooters also have some limitations. The most important outcome of this analysis is the mismatch between the benefits that shared e-scooters could bring in theory (disruptive, green vehicle for short distances) and their negative impacts (e.g., road accidents and pollution). E-scooter-related injuries are increasing rapidly and affect not only riders but also pedestrians. The high accident rate also helps to produce a sense of insecurity. As for environmental issues, shared e-scooters generally pollute more than the transport modes they tend to replace (notably, buses, cycling, and walking) because of unsustainable manufacturing processes, the rental companies' profit-centered business models (e.g., the use of petrol-based vehicles for rebalancing), and the short lifespan of the vehicles. With respect to regulation, the focus is probably on the safety and behavior of riders to a greater extent than with other micro-mobility services. The literature suggests the urgent need for a more holistic, strategic, and collaborative approach, and most of all, a need for these rules to be enforced. In particular, action needs to occur on different fronts, such as developing and implementing rules for good practices in e-scooter production and use, but also adapting our built environment to create spaces that are less car-centered and more friendly to pedestrians, bicycles, and e-scooters.

\subsection{Avenues for Future Research}

On top of what we currently know, some major facets require further exploration. First, too little is still known about how e-scooters users and uses vary between different spatial and socio-economic contexts [86]. Future research will need to collect more genderdisaggregated statistics, look into the reasons for the gender gap in e-scooter use, and investigate its social impacts [87]. Moreover, several studies have suggested a positive correlation between e-scooter use and the bicycle infrastructure, but we lack empirical studies on the relationship with land-use patterns and transport infrastructure not only in urban contexts, but also in suburban and rural environments. Data from e-scooter rental companies might help to fill the current knowledge gap and guide future public policies.

Second, more research is required to identify how the health and environmental impacts of shared e-scooters vary according to local conditions, i.e., factors such as the hire companies' business model, public regulation of e-scooters, the design of the transport system, land-use patterns, etc. The companies' business models in particular can have a significant impact on total vehicle emissions-for example, shared e-scooters in Copenhagen pollute less than in many American cities because the collection and distribution of e-scooters are done using electric vehicles $[15,61,68]$.

Third, as Shaheen and colleagues noted, "additional research is needed to understand the longer-term impacts of [new micro-mobility services] on society and the environment, how they interact with public transportation, and how they may be situated in a larger cultural shift" ([88] p. 259). In particular, it would be pertinent to explore under what conditions the use of shared e-scooters promotes a gradual modal shift towards more active modes of transport and contributes to a decrease in car use and car ownership [89]. It would notably be worth considering whether users of shared e-scooter services tend to become owners after a period of time. The relationship between e-scooter ownership and usage patterns is another interesting topic that has scarcely been explored. The study by Laa and Leth [14] represents the first attempt to investigate these relationships. The authors notably found significant differences in how owners and renters ride e-scooters: while e-scooter trips mostly replace walking and public transport in both groups, e-scooter 
owners also show a considerable shift away from car trips. In addition, the influence of MaaS platforms on shared e-scooter usage seems highly significant [90]. Finally, in terms of health impacts, while the physical injuries associated with e-scooter use are well documented, little is yet known about the long-term effects of e-scooter riding: does it promote sedentary lifestyles? Is it linked to increased obesity? Are riders more exposed to air pollution? Future studies should also consider new safety issues such as the impact of banning e-scooter use on pavements.

Some authors (e.g., [91]) wondered whether shared e-scooters services represent a temporary trend or a lasting phenomenon. According to a study in the US [40], it might be premature to suggest a definitive answer. The authors argue that the success of e-scooter programs might be linked to specific local factors and notably to residents' demand for car-free mobility. Moreover, the rapid rise and decline in dockless bike companies in China have shown how disastrous it could be for both cities and private investors to introduce new micro-mobility services without proper management strategies [92]. However, an international study [21] suggests that the importance of e-scooters is expected to grow and that they could challenge existing transport systems. Overall, in the pre-pandemic world, e-scooter usage seemed to be on the rise but their future in the mobility landscape was still unclear. The impacts of the COVID-19 pandemic on the e-scooter market need to be analyzed, since many US-based companies have had to suspend their services for several months [22].

Author Contributions: Conceptualization, A.A. and A.D.B.; methodology, A.D.B.; software, A.D.B.; validation, A.A. and A.D.B.; formal analysis, A.D.B.; investigation, A.D.B.; resources, A.D.B.; data curation, A.D.B.; writing—original draft preparation, A.D.B.; writing—review and editing, A.A. and A.D.B.; visualization, A.A. and A.D.B.; supervision, A.A.; project administration, A.A. Both authors have read and agreed to the published version of the manuscript.

Funding: This research received no external funding.

Data Availability Statement: The data of this study are available from the authors upon request.

Acknowledgments: The authors would like to thank the "Urban Planning and City Branding" program at the EIVP, Université Gustave Eiffel, and especially Eugenia Llamas-Hernansanz for her valuable support throughout the project.

Conflicts of Interest: The authors declare no conflict of interest.

\section{References}

1. Bloom, M.B.; Noorzad, A.; Lin, C.; Little, M.; Lee, E.Y.; Margulies, D.R.; Torbati, S.S. Standing electric scooter injuries: Impact on a community. Am. J. Surg. 2021, 221, 227-232. [CrossRef]

2. Fitt, H.; Curl, A. The early days of shared micromobility: A social practices approach. J. Transp. Geogr. 2020, 86, 102779. [CrossRef]

3. Rose, J.; Schellong, D. How E-Scooters Can Win a Place in Urban Transport. BCG Global. Available online: https://www.bcg. com/publications/2020/e-scooters-can-win-place-in-urban-transport (accessed on 1 March 2021).

4. Shibayama, T.; Emberger, G. New mobility services: Taxonomy, innovation and the role of ICTs. Transp. Policy 2020, 98, 79-90. [CrossRef]

5. Le Boennec, R.; Nicolaï, I.; Da Costa, P. Assessing 50 innovative mobility offers in low-density areas: A French application using a two-step decision-aid method. Transp. Policy 2019, 83, 13-25. [CrossRef]

6. Santacreu, A.; Yannis, G.; de Saint Leon, O.; Crist, P. Safe Micromobility. 2020. Available online: https://trid.trb.org/view/1696177 (accessed on 10 September 2020).

7. McQueen, M.; Abou-Zeid, G.; MacArthur, J.; Clifton, K. Transportation Transformation: Is Micromobility Making a Macro Impact on Sustainability? J. Plan. Lit. 2020, 36, 46-61. [CrossRef]

8. Campisi, T.; Akgün, N.; Tesoriere, G. An ordered logit model for predicting the willingness of renting micro mobility in urban shared streets: A case study in Palermo, Italy. In Computational Science and Its Applications-ICCSA; Lecture Notes in Computer Science; Gervasi, O., Murgante, B., Misra, S., Garau, C., Blečić, I., Taniar, D., Apduhan, B.O., Eds.; Springer International Publishing: Cham, Switzerland, 2020; pp. 796-808. [CrossRef]

9. Shaheen, S.; Cohen, A. Shared Micromoblity Policy Toolkit: Docked and Dockless Bike and Scooter Sharing. Institute of Transportation Studies, Berkeley. 2019. Available online: https:/ / escholarship.org/uc/item/00k897b5 (accessed on 10 June 2020).

10. Hall, M. Bird Scooters Flying Around Town. Santa Monica Daily Press. Available online: https://www.smdp.com/bird-scootersflying-around-town/162647 (accessed on 11 May 2020). 
11. Clewlow, R. The Micro-Mobility Revolution: The Introduction and Adoption of Electric Scooters in the United States. Populus. 2018. Available online: https:/ / www.populus.ai/micro-mobility-2018-july (accessed on 10 September 2020).

12. NACTO. Shared Micromobility in the U.S. 2018. 2019. Available online: https://nacto.org/wp-content/uploads/2019/04/ NACTO_Shared-Micromobility-in-2018_Web.pdf (accessed on 12 March 2020).

13. de Bortoli, A.; Christoforou, Z. Consequential LCA for territorial and multimodal transportation policies: Method and application to the free-floating e-scooter disruption in Paris. J. Clean. Prod. 2020, 273, 122898. [CrossRef]

14. Laa, B.; Leth, U. Survey of E-scooter users in Vienna: Who they are and how they ride. J. Transp. Geogr. 2020, 89, 102874. [CrossRef]

15. Moreau, H.; Meux, L.D.J.D.; Zeller, V.; D’Ans, P.; Ruwet, C.; Achten, W.M. Dockless E-Scooter: A Green Solution for Mobility? Comparative Case Study between Dockless E-Scooters, Displaced Transport, and Personal E-Scooters. Sustainability 2020, 12, 1803. [CrossRef]

16. Mitchell, G.; Tsao, H.; Randell, T.; Marks, J.; Mackay, P. Impact of electric scooters to a tertiary emergency department: 8-week review after implementation of a scooter share scheme. Emerg. Med. Australas. 2019, 31, 930-934. [CrossRef] [PubMed]

17. Zhu, R.; Zhang, X.; Kondor, D.; Santi, P.; Ratti, C. Understanding spatio-temporal heterogeneity of bike-sharing and scootersharing mobility. Comput. Environ. Urban Syst. 2020, 81, 101483. [CrossRef]

18. Toll, M. Bien Venidos to Lime Electric Scooters as They Expand into Latin America. Electrek. Available online: https://electrek. co/2019/06/26/lime-electric-scooters-expand-latin-america/ (accessed on 12 February 2020).

19. NUMO. Micromobility Map. Available online: https://www.numo.global/new-mobility-atlas (accessed on 12 July 2020).

20. NACTO. Shared Micromobility in the U.S. 2019. 2020. Available online: https://nacto.org/wp-content/uploads/2020/08/2020 bikesharesnapshot.pdf (accessed on 11 May 2020).

21. Gössling, S. Integrating e-scooters in urban transportation: Problems, policies, and the prospect of system change. Transp. Res. Part D Transp. Environ. 2020, 79, 102230. [CrossRef]

22. Button, K.; Frye, H.; Reaves, D. Economic regulation and E-scooter networks in the USA. Res. Transp. Econ. 2020, 84, 100973. [CrossRef]

23. Schellong, D.; Sadek, P.; Schaetzberger, C.; Barrack, T. The Promise and Pitfalls of E-Scooter Sharing. BCG Global. Available online: https:/ / www.bcg.com/publications/2019/promise-pitfalls-e-scooter-sharing (accessed on 10 September 2020).

24. Laa, B.; Emberger, G. Bike sharing: Regulatory options for conflicting interests-Case study Vienna. Transp. Policy 2020, 98, 148-157. [CrossRef]

25. Milakis, D.; Gedhardt, L.; Ehebrecht, D.; Lenz, B. Is micro-mobility sustainable? An overview of implications for accessibility, air pollution, safety, physical activity and subjective wellbeing. In Handbook of Sustainable Transport; Curtis, C., Ed.; Edward Elgar Publishing: Cheltenham, UK, 2020; pp. 180-189. Available online: https://www.elgaronline.com/view/edcoll/9781789900460/ 9781789900460.00030.xml (accessed on 22 February 2021).

26. Fishman, E.; Cherry, C. E-bikes in the Mainstream: Reviewing a Decade of Research. Transp. Rev. 2015, 36, 72-91. [CrossRef]

27. Teixeira, J.F.; Silva, C.; e Sá, F.M. Empirical evidence on the impacts of bikesharing: A literature review. Transp. Rev. 2020, 41, 329-351. [CrossRef]

28. O'Hern, S.; Estgfaeller, N. A scientometric review of powered micromobility. Sustainability 2020, 12, 9505. [CrossRef]

29. Şengül, B.; Mostofi, H. Impacts of E-Micromobility on the Sustainability of Urban Transportation-A Systematic Review. Appl. Sci. 2021, 11, 5851. [CrossRef]

30. James, O.; Swiderski, J.; Hicks, J.; Teoman, D.; Buehler, R. Pedestrians and E-Scooters: An Initial Look at E-Scooter Parking and Perceptions by Riders and Non-Riders. Sustainability 2019, 11, 5591. [CrossRef]

31. Van Wee, B.; Banister, D. How to Write a Literature Review Paper? Transp. Rev. 2016, 36, 278-288. [CrossRef]

32. Denscombe, M. The Good Research Guide: For Small-Scale Social Research Projects, 2nd ed.; Open University Press: Maidenhead, UK, 2003.

33. Degele, J.; Gorr, A.; Haas, K.; Kormann, D.; Krauss, S.; Lipinski, P.; Tenbih, M.; Koppenhoefer, C.; Fauser, J.; Hertweck, D. Identifying e-scooter sharing customer segments using clustering. In Proceedings of the 2018 IEEE International Conference on Engineering, Technology and Innovation (ICE/ITMC), Stuttgart, Germany, 17-20 June 2018; pp. 1-8. [CrossRef]

34. McKenzie, G. Urban mobility in the sharing economy: A spatiotemporal comparison of shared mobility services. Comput. Environ. Urban Syst. 2020, 79, 101418. [CrossRef]

35. Zou, Z.; Younes, H.; Erdoğan, S.; Wu, J. Exploratory Analysis of Real-Time E-Scooter Trip Data in Washington, D.C. Transp. Res. Rec. J. Transp. Res. Board 2020, 2674, 285-299. [CrossRef]

36. Siman-Tov, M.; Radomislensky, I.; Israel Trauma Group; Peleg, K. The casualties from electric bike and motorized scooter road accidents. Traffic Inj. Prev. 2017, 18, 318-323. [CrossRef]

37. Sikka, N.; Vila, C.; Stratton, M.; Ghassemi, M.; Pourmand, A. Sharing the sidewalk: A case of E-scooter related pedestrian injury. Am. J. Emerg. Med. 2019, 37, 1807.e5-1807.e7. [CrossRef] [PubMed]

38. Civity Management Consultants. E-scooters in Germany. A Data-Driven Contribution to the Ongoing Debate. 2019. Available online: https: / / scooters.civity.de/en (accessed on 12 June 2020).

39. 6t-Bureau De Recherche. Uses and Users of Free-Floating Electric Scooters in France. Available online: https: / /6-t.co/en/freefloating-escooters-france/ (accessed on 10 September 2020). 
40. Bai, S.; Jiao, J. Dockless E-scooter usage patterns and urban built Environments: A comparison study of Austin, TX, and Minneapolis, MN. Travel Behav. Soc. 2020, 20, 264-272. [CrossRef]

41. Reed, T. Micromobility Potential in the US, UK and Germany. 2019. Available online: https://trid.trb.org/view/1650977 (accessed on 10 September 2020).

42. Mathew, J.; Liu, M.; Seeder, S.; Li, H.; Bullock, D. Analysis of e-scooter trips and their temporal usage patterns. Inst. Transp. Eng. 2019, 89, 44-49.

43. Noland, R.B. Trip patterns and revenue of shared e-scooters in Louisville, Kentucky. Transp. Find. 2019, 7747. [CrossRef]

44. Espinoza, W.; Howard, M.; Lane, J.; Van Hentenryck, P. Shared e-scooters: Business, pleasure, or transit? arXiv 2019, arXiv:1910.05807.

45. McKenzie, G. Spatiotemporal comparative analysis of scooter-share and bike-share usage patterns in Washington, D.C. J. Transp. Geogr. 2019, 78, 19-28. [CrossRef]

46. McKenzie, G. Shared micro-mobility patterns as measures of city similarity: Position paper. In Proceedings of the 1st ACM SIGSPATIAL International Workshop on Computing with Multifaceted Movement Data-MOVE'19, Chicago, IL, USA, 5 November 2019; pp. 1-4. [CrossRef]

47. Caspi, O.; Smart, M.J.; Noland, R.B. Spatial associations of dockless shared e-scooter usage. Transp. Res. Part D Transp. Environ. 2020, 86, 102396. [CrossRef]

48. Curl, A.; Fitt, H. Same same, but different? Cycling and e-scootering in a rapidly changing urban transport landscape. N. Z. Geogr. 2020, 76, 194-206. [CrossRef]

49. Sanders, R.L.; Branion-Calles, M.; Nelson, T.A. To scoot or not to scoot: Findings from a recent survey about the benefits and barriers of using E-scooters for riders and non-riders. Transp. Res. Part A Policy Pr. 2020, 139, 217-227. [CrossRef]

50. Bieliński, T.; Agnieszka, W. Electric Scooter Sharing and Bike Sharing User Behaviour and Characteristics. Sustainability 2020, 12, 9640. [CrossRef]

51. Davies, N.; Blazejewski, L.; Sherriff, G. The rise of micromobilities at tourism destinations. J. Tour. Futur. 2020, 6, 209-212. [CrossRef]

52. Lee, M.; Chow, J.Y.J.; Yoon, G.; He, B.Y. Forecasting e-scooter competition with direct and access trips by mode and distance in New York City. arXiv 2019, arXiv:1908.08127.

53. Alwani, M.; Jones, A.J.; Sandelski, M.; Bandali, E.; Lancaster, B.; Sim, M.W.; Shipchandler, T.; Ting, J. Facing Facts: Facial Injuries from Stand-up Electric Scooters. Cureus 2020, 12, e6663. [CrossRef]

54. Badeau, A.; Carman, C.; Newman, M.; Steenblik, J.; Carlson, M.; Madsen, T. Emergency department visits for electric scooterrelated injuries after introduction of an urban rental program. Am. J. Emerg. Med. 2019, 37, 1531-1533. [CrossRef]

55. Kobayashi, L.M.; Williams, E.; Brown, C.V.; Emigh, B.J.; Bansal, V.; Badiee, J.; Checchi, K.D.; Castillo, E.M.; Doucet, J. The e-merging e-pidemic of e-scooters. Trauma Surg. Acute Care Open 2019, 4, e000337. [CrossRef]

56. Trivedi, T.K.; Liu, C.; Antonio, A.L.M.; Wheaton, N.; Kreger, V.; Yap, A.; Schriger, D.; Elmore, J.G. Injuries Associated with Standing Electric Scooter Use. JAMA Netw. Open 2019, 2, e187381. [CrossRef]

57. Lipovsky, C. Free-floating electric scooters: Representation in French mainstream media. Int. J. Sustain. Transp. 2020, 1-10. [CrossRef]

58. Haworth, N.L.; Schramm, A. Illegal and risky riding of electric scooters in Brisbane. Med. J. Aust. 2019, 211, 412-413. [CrossRef]

59. Allem, J.-P.; Majmundar, A. Are electric scooters promoted on social media with safety in mind? A case study on Bird's Instagram. Prev. Med. Rep. 2019, 13, 62-63. [CrossRef]

60. Mayhew, L.J.; Bergin, C.; Schaetzberger, C.; Hill, J. Impact of e-scooter injuries on emergency department imaging. J. Med. Imaging Radiat. Oncol. 2019, 63, 461-466. [CrossRef]

61. Berge, S.H. Kickstarting Micromobility - A Pilot Study on E-Scooters (1721/2019, 4763); Institute of Transport Economics: Oslo, Norway, 2019. Available online: https:/ / www.toi.no/getfile.php/1350932/Publikasjoner/T \T1\OI\%20rapporter/2019/17212019/1721-2019-elektronisk.pdf (accessed on 10 September 2020).

62. Tice, P.C. Micromobility and the Built Environment. Proc. Hum. Factors Ergon. Soc. Annu. Meet. 2019, 63, 929-932. [CrossRef]

63. Hardt, C.; Bogenberger, K. Usage of e-Scooters in Urban Environments. Transp. Res. Procedia 2019, 37, 155-162. [CrossRef]

64. Lo, D.; Mintrom, C.; Robinson, K.; Thomas, R. Shared micromobility: The influence of regulation on travel mode choice. N. Z. Geogr. 2020, 76, 135-146. [CrossRef]

65. Glenn, J.; Bluth, M.; Christianson, M.; Pressley, J.; Taylor, A.; Macfarlane, G.S.; Chaney, R.A. Considering the Potential Health Impacts of Electric Scooters: An Analysis of User Reported Behaviors in Provo, Utah. Int. J. Environ. Res. Public Health 2020, 17, 6344. [CrossRef]

66. Tillemann, L.; Feasley, L. Let's Count the Ways E-Scooters Could Save the City. Wired. Available online: https://www.wired. com/story / e-scooter-micromobility-infographics-cost-emissions / (accessed on 10 September 2020).

67. Neven, A.; Verstrael, A.; Janssen, A.; Dendale, P. Transport as a new avenue for CV prevention in city dwellers: How to kill two birds with one stone? Eur. Heart J. 2020, 41, 816-817. [CrossRef]

68. Hollingsworth, J.; Copeland, B.; Johnson, J. Are e-scooters polluters? The environmental impacts of shared dockless electric scooters. Environ. Res. Lett. 2019, 14, 084031. [CrossRef]

69. Lime. Year-End Report. 2018. Available online: https://www.li.me/hubfs/Lime_Year-End\%20Report_2018.pdf (accessed on 1 February 2020). 
70. Martinez-Navarro, A.; Cloquell-Ballester, V.-A.; Segui-Chilet, S. Photovoltaic Electric Scooter Charger Dock for the Development of Sustainable Mobility in Urban Environments. IEEE Access 2020, 8, 169486-169495. [CrossRef]

71. Finck, M.; Lamping, M.; Moscon, V.; Richter, H. Smart Urban Mobility as a Regulatory Challenge. In Smart Urban Mobility: Law, Regulation, and Policy; Finck, M., Lamping, M., Moscon, V., Richter, H., Eds.; Springer: Heidelberg, Germany, 2020 ; pp. 1-17. [CrossRef]

72. Bartling, H. Urban mobilities and local regulation: Transportation challenges and promise of the sharing economy. In Handbook of the Sharing Economy; Belk, R.W., Eckhardt, G.M., Bardhi, F., Eds.; Edward Elgar Publishing: Cheltenham, UK, 2020; pp. 230241. Available online: https://www.elgaronline.com/view/edcoll/9781788110532/9781788110532.00027.xml (accessed on 19 February 2021).

73. Shaheen, S.; Cohen, A.; Zohdy, I. Shared mobility resources: Helping to understand emerging shifts in transportation. Policy Briefs 2017, 18. [CrossRef]

74. Turoń, K.; Czech, P. The concept of rules and recommendations for riding shared and private e-scooters in the road network in the light of global problems. In Modern Traffic Engineering in the System Approach to the Development of Traffic Networks; Macioszek, E., Sierpiński, G., Eds.; Springer International Publishing: Cham, Switzerland, 2019; pp. 275-284. [CrossRef]

75. Giles, C. When Can I Ride n E-Scooter Legally? BBC News. Available online: https://www.bbc.com/news/uk-48106617 (accessed on 4 January 2021).

76. Florek-Klęsk, D. Electric Scooters and the Safety of Road Users-Selected Legal Aspects. Mod. Manag. Rev. 2019, 24, 7. [CrossRef]

77. Brown, A.; Klein, N.J.; Thigpen, C.; Williams, N. Impeding access: The frequency and characteristics of improper scooter, bike, and car parking. Transp. Res. Interdiscip. Perspect. 2020, 4, 100099. [CrossRef]

78. Transportation for America. Shared Micromobility Playbook. 2018. Available online: https://playbook.t4america.org/ (accessed on 5 January 2021).

79. Ruhrort, L. Reassessing the Role of Shared Mobility Services in a Transport Transition: Can They Contribute the Rise of an Alternative Socio-Technical Regime of Mobility? Sustainability 2020, 12, 8253. [CrossRef]

80. Noussan, M.; Hafner, M.; Tagliapietra, S. The Future of Transport Between Digitalization and Decarbonization: Trends, Strategies and Effects on Energy Consumption; Springer International Publishing: Cham, Switzerland, 2020. [CrossRef]

81. Riggs, W.; Kawashima, M. Exploring Best Practice for Municipal E-Scooter Policy in the United States. 2020. Available online: https: / / www.ssrn.com/abstract=3512725 (accessed on 25 November 2020).

82. Laker, L. Welcome, Watch or Ban: How Should Cities Deal with Electric Scooters? The Guardian. Available online: https: //www.theguardian.com/cities/2019/jun/18/welcome-watch-or-ban-how-should-cities-deal-with-electric-scooters (accessed on 9 October 2020).

83. Janssen, C.; Barbour, W.; Hafkenschiel, E.; Abkowitz, M.; Philip, C.; Work, D.B. City-to-City and Temporal Assessment of Peer City Scooter Policy. Transp. Res. Rec. J. Transp. Res. Board 2020, 2674, 219-232. [CrossRef]

84. Li, L.; Lee, K.Y.; Yang, S.-B.; Chang, L.Y. Linking Privacy Concerns for Traceable Information and Information Privacy Protective Responses on Electric Scooter Sharing Platforms. In Proceedings of the 53rd Hawaii International Conference on System Sciences, Maui, HI, USA, 7-10 January 2020. [CrossRef]

85. Oeschger, G.; Carroll, P.; Caulfield, B. Micromobility and public transport integration: The current state of knowledge. Transp. Res. Part D Transp. Environ. 2020, 89, 102628. [CrossRef]

86. Hosseinzadeh, A.; Algomaiah, M.; Kluger, R.; Li, Z. E-scooters and sustainability: Investigating the relationship between the density of E-scooter trips and characteristics of sustainable urban development. Sustain. Cities Soc. 2021, 66, 102624. [CrossRef]

87. Daniel, S. Some Gender Equality and Equity Planning Cases in Urban Planning in Malmö, or How I Became a Transport Feminist. In Gendering Smart Mobilities; Priya, U.T., Christensen, H.R., Levin, L., Eds.; Routledge: London, UK, 2020.

88. Shaheen, S.; Cohen, A.; Chan, N.; Bansal, A. Sharing Strategies: Carsharing, shared micromobility (bikesharing and scooter sharing), transportation network companies, microtransit, and other innovative mobility modes. In Transportation, Land Use, and Environmental Planning; Elsevier: Amsterdam, The Netherlands, 2020; pp. 237-262. [CrossRef]

89. Aguilera, A.; Cacciari, J. Living with fewer cars: Review and challenges on household demotorization. Transp. Rev. 2020, 40, 796-809. [CrossRef]

90. Hensher, D.; Mulley, C.; Ho, C.; Wong, Y.; Smith, G.; Nelson, J. Understanding Mobility as a Service (MaaS): Past, Present and Future; Elsevier: Amsterdam, The Netherlands, 2020. [CrossRef]

91. Chang, A.Y.; Miranda-Moreno, L.; Clewlow, R.; Sun, L. Trend or Fad? Deciphering the Enablers of Micromobility in the U.S. SAE International. 2019. Available online: https://www.sae.org/binaries/content/assets/cm/content/topics/micromobility/saemicromobility-trend-or-fad-report.pdf (accessed on 6 October 2020).

92. The Economist. Lessons from the Fall of China's Bike-Sharing Pioneer. Available online: https://www.economist.com/business/ 2019/01/26/lessons-from-the-fall-of-chinas-bike-sharing-pioneer (accessed on 11 January 2021). 